\title{
Minimal Reporting Standards for Active Middle Ear Hearing Implants
}

\author{
Hannes Maier ${ }^{a} \quad$ Uwe Baumann $^{\mathrm{b}} \quad$ Wolf-Dieter Baumgartner ${ }^{\mathrm{c}}$ \\ Dirk Beutner $^{d}$ Marco D. Caversaccio ${ }^{e}$ Thomas Keintzel $^{f}$ Martin Kompis ${ }^{e}$ \\ Thomas Lenarz $^{\mathrm{a}} \quad$ Astrid Magele $^{\mathrm{g}}$ Torsten Mewes $^{\mathrm{h}} \quad$ Alexander Müller $^{\mathrm{i}}$ \\ Tobias Rader ${ }^{j}$ Torsten Rahne $^{k}$ Sebastian P. Schraven' Burkard Schwab ${ }^{m}$ \\ Georg Mathias Sprinzl ${ }^{9}$ Bernd Strauchmann ${ }^{n}$ Ingo Todt ${ }^{\circ}$ Thomas Wesarg ${ }^{p}$ \\ Barbara Wollenberg ${ }^{q}$ Stefan K. Plontke ${ }^{k}$ \\ ${ }^{\text {a }}$ Department of Otorhinolaryngology, Hannover Medical School, Hannover, Germany; ${ }^{b}$ University Hospital \\ Frankfurt, ENT/Audiological Acoustics, Frankfurt, Germany; ' Department of ENT, Medical University of Vienna,

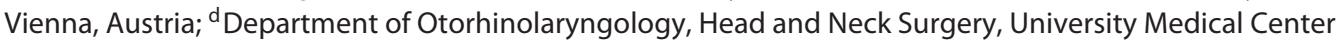 \\ Göttingen, Göttingen, Germany; ' University Hospital, Inselspital Department of ORL, Head and Neck Surgery, Bern, \\ Switzerland; ' Department of Otorhinolaryngology, Klinikum Wels-Grieskirchen, Wels, Austria; ${ }^{9}$ University Clinic \\ St. Poelten, St. Poelten, Austria; ${ }^{\text {h} H e l i o s ~ D r . ~ H o r s t ~ S c h m i d t ~ K l i n i k e n ~ W i e s b a d e n, ~ W i e s b a d e n, ~ G e r m a n y ; ~}{ }^{\text {Vivantes }}$ \\ Hearing Center, ORL Department Friedrichshain Clinic, Berlin, Germany; ${ }^{j}$ Department of Otolaryngology and Head \\ and Neck Surgery, Audiological Acoustics, University of Mainz, Mainz, Germany; ${ }^{k}$ Department of Otolaryngology \\ and Head and Neck Surgery, Martin Luther University Halle-Wittenberg, Halle (Saale), Germany; 'Department of \\ Otorhinolaryngology, Head and Neck Surgery "Otto Koerner", University Medical Center Rostock, Rostock, Germany; \\ ${ }^{m}$ Helios Klinikum Hildesheim, Hildesheim, Germany; ${ }^{n}$ Department of Otorhinolaryngology, UniversityHospital \\ Zürich, Head and Neck Surgery, Zürich, Switzerland; ${ }^{\circ}$ Department of Otolaryngology, Klinikum Bielefeld, Head and

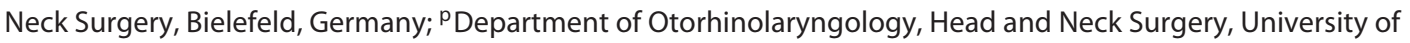 \\ Freiburg Medical Center, Freiburg, Germany; ${ }^{9}$ Clinic for Otorhinolaryngology, Head and Neck Surgery, University \\ Clinic Schleswig Holstein, Campus Lübeck, Lübeck, Germany
}

\section{Keywords}

Hearing loss - Reporting standards · Hearing outcome · Hearing results · Audiogram - Review · Meta-analysis . Active middle ear implant

\footnotetext{
Abstract

There is currently no standardized method for reporting audiological, surgical and subjective outcome measures in clinical trials with active middle ear implants (AMEls). It is often
}

difficult to compare studies due to data incompatibility and to perform meta-analyses across different centres is almost impossible. A committee of ENT and audiological experts from Germany, Austria and Switzerland decided to address this issue by developing new minimal standards for reporting the outcomes of AMEI clinical trials. The consensus presented here aims to provide a recommendation to enable better inter-study comparability.

(c) 2018 The Author(s)

Published by S. Karger AG, Basel

\begin{tabular}{ll}
\hline KARGER & $\begin{array}{c}\text { @ } 2018 \text { The Author(s) } \\
\text { Published by S. Karger AG, Basel Open carcess }\end{array}$ \\
E-Mail karger@karger.com & This article is licensed under the Creative Commons Attribution- \\
www.karger.com/aud & $\begin{array}{l}\text { NonCommercial-NoDerivatives 4.0 International License (CC BY- } \\
\text { NC-ND) (http://www.karger.com/Services/OpenAccessicense). } \\
\text { Usage and distribution for commercial purposes as well as any dis- } \\
\text { tribution of modified material requires written permission. }\end{array}$
\end{tabular}

Prof. Hannes Maier

Department of Otorhinolaryngology and Cluster of Excellence "Hearing4all" Hannover Medical School, Carl-Neuberg-Strasse 1

DE-30625 Hannover (Germany)

E-Mail maier.hannes@mh-hannover.de 


\section{Introduction}

Since its formation in 2008, the HEARRING network has established quality standards for hearing implants, specifying the resources that are required for clinical practice as well as the necessary aspects of providing the best care from patient referral and selection up to longterm follow-up and maintenance. HEARRING consists of a group of leading experts in the field of hearing implants who "are committed to leading the exploration of new avenues of research in hearing implant science, to advancing clinical procedures and to developing and perfecting surgical techniques" (http://www.hearring.com). Quality standards are now available for cochlear implants (CI), Electro-Acoustic Stimulation (EAS) systems, (active) middle ear implants ([A]MEIs) and bone conduction implants (BCIs) [Godey, 2013; Hagen, 2013; Martin and Raine, 2013]. However, these standards focus mainly on improving clinical practice but provide limited information about the essential audiological data set of results and how they should be reported. In order to identify a common ground for international multicentre research and collaboration, HEARRING members reached a consensus on minimal outcome measurements, mainly for CI [Kleine Punte and Van de Heyning, 2013]. An equivalent consensus on active middle ear implants (AMEIs) is lacking.

Middle ear implants are emerging as an important treatment option, with results being reported from various sites, each with limited numbers of cases. This situation is even more complicated by the fact that AMEIs have been successfully used in dysfunctional middle ears with different coupling modalities to residues of the ossicular chain, the cochlear windows or even artificially created windows. While competent judgement and statistically sound evidence require pooling data from different sources, this is currently difficult or impossible with the heterogeneous sets of data being reported. Defining a core dataset that can be extended according to the specific needs of the investigated application would enable comparison and pooling of results to create convincing evidence in meta-analyses. Ultimately, the outcome will be differential, better defined indication criteria as well as the possibility for cross-site comparison and determination of long-term results.

A minimal reporting standard for the full range of hearing loss treatments was introduced by the AAO-HNS Hearing Committee but does not include key parameters. Although defined as standard for reporting in several international peer-reviewed ENT journals, the required re- sults do not reflect the dataset necessary to allow differentiated conclusions about the risks and treatment success with AMEIs. Minimum outcome measures to be reported included air conduction (AC) pure tone thresholds and word recognition scores (WRS) only [Gurgel et al., 2012]. These two measures are important to determine the success of a treatment but do not sufficiently facilitate detailed statistical analysis to provide conclusive evidence. In addition, the proposed WRS measure ( $40 \mathrm{~dB}$ above sensation level, SL) is not uniformly accepted, and the suggested form of a matrix plot hinders effective sample size calculations for planning clinical trials. Moreover, AC thresholds and WRS alone are not enough to make regulatory decisions, since the safety of the procedure and an improvement in the patient's quality of life (QoL) need to be considered as well. Furthermore, the way adverse events (AEs) and QoL measures are reported in studies differs widely. Many systematic reviews on these topics have been unable to pool results and to carry out metaanalyses due to heterogeneity of data [Bond et al., 2009; Colquitt et al., 2011; Johnson et al., 2006; Klein et al., 2012; 2013]. Determining reporting standards for these outcome measures would not only allow clinicians to compare patients' results to optimize their practice but would also aid manufacturers by the creation of sufficient data to gain and maintain market approval. Additionally, policy makers would be better able to make comparisons between devices and decide about reimbursement strategies.

\section{Scope}

In regard to the issues mentioned above, the following consensus was established by a group of ENT and audiological experts from Germany, Austria and Switzerland. The paper comprises minimal reporting standards on safety, surgical, audiological and QoL outcomes for AMEIs. Although designed initially for the assessment of German speaking subjects, the simplicity of this proposal makes it easily extendable to other languages.

These recommendations refer to AMEIs, which consist of all active, partially or totally implantable hearing implants in which the vibratory output drives any part of the middle ear including the ossicles or the bordering anatomical structures to the inner ear, namely, the round window or the perforated or unperforated stapes footplate. These AMEIs can treat sensorineural, conductive or mixed hearing losses.

Although these recommendations do not, in principle, extend to implantable bone conduction devices in which vibrations are delivered to the skull outside of the middle 
ear, we would like to point out that they can also be applied to most applications of this group of devices. However, these recommendations explicitly do not extend to the application of single-sided deafness.

These standards aim to provide the researcher with a list of tests a study should cover to ensure comparability of results and acceptance by the wider research community. Review boards would be able to improve the quality of AMEI-related publications by applying these standards as criteria to evaluate articles. Manufacturers who implement these minimal standards will be able to ensure that data are comparable across studies, enabeling the pooling of data. In addition, the minimal reporting standards proposed here cover information that has to be obtained as a basis for regulatory decision-making and which was missing in the previously published reporting standards [Gurgel et al., 2012].

Our recommendations for minimal reporting standards focus on the performance of the device, the risks and benefits for the patient and the patient's quality of life. Three different approaches were incorporated to fulfill this: (1) For the description of procedure-specific properties, surgical information has to be reported. (2) The device performance should be assessed via audiological tests as described, initially monaurally. The focus was put on monaural evaluation, as we consider a framework that allows for the collection of device- and application-specific data to be the priority. This enables the generation of device-relevant technical meta-data and does not question the importance of binaurally-determined results that better reflect the impact on the patient's life and can be assessed optionally. (3) As the questionnaires also encompass the binaural input in daily life, the focus is here on the individual real-world experience and quality of life.

\section{Methods}

Initiated by MED-EL Inc. (Innsbruck, Austria), a group of clinical specialists and researchers from Germany, Austria and Switzerland was formed. Surgeons ( $n=$ $11)$ and audiologists $(n=8)$ were included in order to encompass all important aspects of AMEIs for reporting standards. Most of the participants were members of national or international audiological societies (ADANO, EFAS, DGA or EAONO), including board members. However, the initiative here was driven by individuals and no official mandate was sought.

The participants recognize that the AMEI field is evolving rapidly and is likely to continue to advance fur- ther. One clearly declared aim was therefore to generate recommendations which are useful and applicable to all current and future AMEIs, strictly independent of any specific device or manufacturer. The "World Café" methodology [Fouché and Light, 2011; Stewart, 2005] was used to form consensus-driven agreement on reporting standards covering the topics of medical and surgical procedures, as well as audiological, safety and subjective outcomes.

\section{Reporting of Outcomes}

Stakeholders identified a core group of minimal standards they considered to be essential to report when publishing data on AMEIs. For practicality, the outcomes are divided into pre- and post-operative procedures.

\section{Demographics}

A table containing patient demographics including etiology and previous surgical interventions should be included. Usage of hearing devices before AMEI implantation should also be reported in this table. Inclusion of patients with indications for devices outside of the intended use by the manufacturer needs to be clearly mentioned with a short explanation about the reasons behind this.

\section{Medical and Surgical Reporting Standards}

Hearing rehabilitation outcomes with an AMEI are related to the underlying medical problem, that is otological and audiological and the implantable hearing system used, as well as the surgical procedures undertaken. There are various surgical methods used both to address the otological disease in general and to couple the AMEI to the inner ear for energy transfer. While disease classification and staging and description of the surgical procedure is very similar to conventional middle ear and temporal bone surgery, some aspects are specific to the usage of AMEIs for hearing rehabilitation.

\section{Reporting of Preoperative Characteristics}

Data should be reported for individual patients (see online suppl. Table 1; for all online suppl. material, see www. karger.com/doi/10.1159/000490878 for version 1.0 (updated versions can be found at https://cdn.hno.org/media/publikationen/minimal_standards_for_AMEI_ v1.0.xlsx and https://www.dga-ev.com/fachausschuesse/). This enables significantly more valuable data extraction for systematic reviews and meta-analysis. 
The general medical/otological diagnosis should be described/classified, as well as the patient's indication for an AMEI, that is, the medical or audiological condition that makes hearing rehabilitation with a conventional hearing aid impossible or insufficient. This comprises the following conditions, among others: chronic otitis media, chronic adhesive otitis media, cholesteatoma, mastoiditis, sclerotic middle ear disease (tympanosclerosis, middle ear fibrosis), otosclerosis, traumatic ossicular chain disruption, chronic ear canal infection, recurrent postinflammatory meatal fibrosis, eczema of the ear canal, chronic ear canal pain or middle ear/ear canal malformation.

Many patients have had multiple previous surgeries, and the number of surgeries and specifics about the respective ear should be stated (e.g., present open mastoid cavity, labyrinthine fistula of the oval window or stapes footplate fracture, wide exposure of the dura etc.).

In cases of malformation, the important aspects of the malformation should be described, especially with respect to pneumatization and/or size of the mastoid, the patient's ear canal, the round and oval windows, the ossicles and the course of the facial nerve.

The Jahrsdoerfer and Siegert scores [Jahrsdoerfer et al., 1992; Siegert et al., 1996], developed before AMEIs existed, are more relevant to conventional middle ear surgery in patients with malformations. The AMEI score, however, should be reported as this score allows for a more specific assessment of the probability of success with an AMEI [Frenzel et al., 2013].

Reporting of Surgical and Medical Characteristics

Reporting standards from conventional middle ear and temporal bone surgery contain descriptions of surgical procedures based on the underlying otological problem [American Academy of Otolaryngology - Head and Neck Surgery Foundation, 1995; Becvarovski and Kartush, 2001; Bellucci, 1989; Dornhoffer and Gardner, 2001; Neudert and Zahnert, 2017; Tos, 2008].

AMEI surgery requires the following minimum information related to the surgical procedure to be reported: canal wall up with or without posterior tympanotomy, canal wall down, extent of mastoid obliteration or posterior canal reconstruction in canal wall down techniques, materials for tympanic membrane reconstruction (cartilage, fascia, perichondrium or compound transplants), lateral petrosectomy and external ear canal closure.

It is important to precisely state the method used to couple the AMEI to the inner ear in order to evaluate the quality of energy transfer. Information on whether the
AMEI was coupled to the middle ear structure, to the inner ear fluids via the round window- or oval window membrane or directly into the fluid, should be included. If coupling elements are used, they must be mentioned. If coupling elements are altered or "custom made" by the surgeon to fit the specific anatomical situation, this should be mentioned and identified as "off label use" or "nonapproved". If additional measures, for example, "lifts" for active bone conduction implants, are used, this should be stated. If applicable, the placement of an implant cable should be specified.

The presence or absence of intraoperative or postoperative problems and complications must be reported for at least the first 6 months (the audiological observation period); for example, complications such as ossicle luxation, labyrinthine fistula, bleeding, liquorrhea, bacterial infection of the middle ear or the implant bed, labyrinthitis, acoustic trauma or other sensorineural hearing loss ( (BC) thresholds, see below), vertigo, tinnitus, facial nerve injury, dysgeusia (affection of chorda tympani) dura or sinus conflicts including impression of structures, intracranial complications (bleeding, infection, abscesses) and complications in wound healing or skin irritation at the incision or implant site need to be reported. Late complications, (1 year or more postoperative) including implant or wire extrusion, dislocation of transducer/coupler assembly and loss of coupling (e.g., increase in in situ thresholds) need to be reported, as well as technical complications and device failures. If a revision surgery was necessary, it must be stated whether it was due to medical/ surgical (procedure) or device-related reasons [Ernst et al., 2016; Gavilan et al., 2015; Hobson et al., 2010; Lassaletta et al., 2016; Mohamad et al., 2016; Van Rompaey et al., 2011; Wazen et al., 2011; Zwartenkot et al., 2016].

\section{Reporting Standards for Fitting}

Various well-defined standards for the adjustment of frequency-specific amplification settings (fitting) exist for conventional hearing aids. Commonly used independent fitting rules include NAL-NL1 or DSL I/O and company-specific fitting algorithms may add a "flavor" to define output targets for a specific input level. However, the situation for AMEIs is more complicated because the output strongly depends on the coupling type chosen and varies substantially among individuals. We suggest minimally reporting on the following:

- Which settings (e.g., company default, best threshold, max. output) were used.

- Whether or not a compression was used or temporarily switched off for the determination of thresholds. 
Table 1. Measuring scheme for minimal reporting standards for AMEI devices

\begin{tabular}{|c|c|c|c|}
\hline & Audiological tests & Pre-op & $\begin{array}{l}\text { At least } 6 \text { months } \\
\text { post-activation }\end{array}$ \\
\hline \multirow[t]{2}{*}{$\begin{array}{l}\text { Headphones or bone } \\
\text { conduction headset }\end{array}$} & $\begin{array}{l}\text { Pure-tone audiometry } \\
\mathrm{AC}(0.25-8 \mathrm{kHz}) \text { and } \\
\mathrm{BC}(0.5-6 \mathrm{kHz})\end{array}$ & Bilaterally & At least from implanted side \\
\hline & $\begin{array}{l}\text { Speech audiometry } \\
\text { (WRS at } 65 \text { and } 80 \mathrm{~dB} \mathrm{SPL} / \\
\text { if necessary } \mathrm{WRS}_{\max } \text { ) }\end{array}$ & $\begin{array}{l}\text { At least from implanted side } \\
\text { (optional: bilaterally) }\end{array}$ & \\
\hline \multirow[t]{3}{*}{ Sound field } & $\begin{array}{l}\text { Sound field thresholds } \\
(0.25-8 \mathrm{kHz})\end{array}$ & $\begin{array}{l}\text { Unaided: ear to be implanted } \\
\text { (optional: with optimized } \mathrm{HA}^{1} \\
\text { in the ear to be implanted) }\end{array}$ & $\begin{array}{l}\text { Unaided: implanted ear }{ }^{2} \\
\text { AMEI aided: implanted ear }\end{array}$ \\
\hline & $\begin{array}{l}\text { Sound field speech audiometry } \\
\text { in quiet } \\
\text { (WRS at } 65 \mathrm{~dB} \text { SPL) }\end{array}$ & $\begin{array}{l}\text { Unaided: ear to be implanted } \\
\text { (optional: with optimized } \mathrm{HA}^{1} \\
\text { in the ear to be implanted) }\end{array}$ & $\begin{array}{l}\text { Unaided: implanted ear }{ }^{2} \\
\text { AMEI aided: implanted ear }\end{array}$ \\
\hline & $\begin{array}{l}\text { Sound field speech audiometry } \\
\text { in noise } \\
\left(\mathrm{SRT}_{50} \text {, adaptive, } \mathrm{S}_{0} \mathrm{~N}_{0} \text {, fixed noise }\right. \\
\text { at } 65 \mathrm{~dB} \mathrm{SPL})\end{array}$ & $\begin{array}{l}\text { Unaided: ear to be implanted } \\
\text { (optional: with optimized } \mathrm{HA}^{1} \\
\text { in the ear to be implanted) }\end{array}$ & $\begin{array}{l}\text { Unaided: implanted ear } \\
\text { AMEI aided: implanted ear }\end{array}$ \\
\hline
\end{tabular}

\footnotetext{
${ }^{1}$ An optimized HA is defined as a hearing aid deemed adequate for the current hearing loss and with controlled and optimized fitting. ${ }^{2}$ If there is a change between pre- and post-op pure tone thresholds at any frequency, the unaided setting must be measured and reported as well.
}

As the intention of this paper was to define minimum standards, we limited the essential descriptors for fitting to a few basic ones that are independent of available equipment. Nevertheless, as fitting is crucial for any kind of hearing aid, we encourage reporting beyond the minimum. Here it may be important to include, for example, whether a systematic approach for fine tuning, (e.g. ScalAdapt [Pastoors et al., 2001]) or if a virtual or real-life environment optimization was used. Reporting performed post-fitting controls such as loudness scaling (e.g. ACALOS [Brand and Hohmann, 2002]) could further complete the description of the fitting. Technical features determined during fitting, for example, if the uncomfortable levels were reached by the device or if gain was limited by feedback can provide valuable information on maximum power output (MPO) and limitations.

\section{Audiological Outcomes}

Table 1 shows the minimal set of audiological tests necessary for reporting outcomes obtained with AMEIs. Detailed information about each test is mentioned in the corresponding sections of this paper. For the reliability of post-op results, it is essential that the patients already obtained stable audiological results, which normally can be expected at 6 months after device activation. However, if stable fitting is not achieved within that period, post-op results should be reported at least 1 month after it occurs.

In addition, documentation of (daily) device usage should be gathered either from the patient or preferably from data logging to report on how intensively the device was used or whether it was used at all.

\section{Pure-Tone Audiometry}

Pre-Op Procedures: Clinical pure-tone audiometry with headphones or insert earphones should be measured for each ear separately using adequate masking on the contralateral side. The AC thresholds from 0.25 to $8 \mathrm{kHz}$ $(0.25,0.5,1,2,4,6$ and $8 \mathrm{kHz})$ and $\mathrm{BC}$ thresholds from 0.5 to $6 \mathrm{kHz}(0.5,1,2,4$, and $6 \mathrm{kHz})$ should be reported as frequency-specific averages (mean, median) with appropriate statistical descriptors (N's, standard deviations or percentile ranges).

The individual audiological data should be presented in separate tables at the end of the manuscript (e.g., as 
online suppl. material Table 1, see www.karger.com/ doi/10.1159/000490878 for version 1.0 (updated versions can be found at https://cdn.hno.org/media/publikationen/minimal_standards_for_AMEI_v1.0.xlsx and https://www.dga-ev.com/fachausschuesse/)).

Post-Op Procedures: Post-operative AC and BC thresholds should be reported together with the pre-op puretone audiometry data for at least the implanted ear about 6 months after device activation.

Speech Audiometry

Pre-Op Procedures: The patient's speech perception capability should be estimated by pre-op speech audiometry using headphones or insert earphones on both sides separately. The minimum standard would be to report the WRS for monosyllabic words in percent correct at a fixed sound pressure level (SPL) of 65 and $80 \mathrm{~dB}$ SPL. If the patient only achieves poor word recognition $<60$ WRS (\% correct) [Martin, 2012] at $80 \mathrm{~dB}$ SPL, the sound pressure level should be adjusted in order to find and report the maximum WRS (WRS $\max ^{1}$ ) [Hoppe et al., 2014].

Sound Field Thresholds

Pre-Op Procedures: Sound field thresholds with narrow band noise or warble tones must be reported from $250 \mathrm{~Hz}$ to $8 \mathrm{kHz}(0.25,0.5,1,2,4,6$, and $8 \mathrm{kHz})$ unilaterally for the implanted ear with exclusion of the contralateral ear. We suggest plugging and muffling on the contralateral ear. However, our experience shows that the attenuation achieved by this measure is limited to approximately $30 \mathrm{~dB}(0.5 \mathrm{kHz})$ to $40 \mathrm{~dB}(1-4 \mathrm{kHz})$. Specifically, in asymmetric hearing loss, great care is advised to avoid erroneous results and we suggest masking (if possible) or exclusion of data. The measurements should be done in the unaided and if possible aided conditions, using a hearing aid that has been previously deemed adequate for the current amount of hearing loss and with controlled and optimized fitting (optimized HA). Results from hearing aids that are inappropriate for the patient's hearing loss shall not be included in the study.

Post-Op Procedures: Sound field tests with the AMEI should be carried out in a similar manner to those performed preoperatively. If there is a change between preand post-op pure-tone thresholds $(\mathrm{AC}, \mathrm{BC} \geq 10 \mathrm{~dB}$ ) at any frequency, the unaided sound field audiometry must also be measured and reported. If patients are included in data analysis, and thresholds (BC or AC) are not measur-

${ }^{1}$ Also known as PBmax. able, rules for omission or model-based substitution must be clearly defined. In raw data files, "not measurable" or "not measured" values have to be clearly marked as not measured, not measurable or model-base estimates, and the limits of the measurement devices have to be provided.

\section{Sound Field Speech Audiometry in Quiet}

Pre-Op Procedures: The WRS using monosyllabic words at a presentation level of $65 \mathrm{~dB}$ SPL must be reported in the unaided condition, and if available with an optimized HA in the aided condition. The test should be performed and reported unilaterally (unaided and aided with exclusion of contralateral ear). If 2 hearing aids are available, it is recommended, but optional, to report bilateral WRS with both devices.

Post-Op Procedures: The aided WRS with the AMEI should be assessed and reported using the same conditions that were used preoperatively, and preferably at the same time the sound field thresholds are measured. If there is a change between unaided pre- and post-op puretone thresholds, the unaided WRS should also be measured and reported post-op.

\section{Sound Field Speech Audiometry in Noise}

Pre-Op Procedures: For speech in noise testing, we recommend the application of an adaptive test to determine the speech recognition threshold (SRT) in noise (as dB SNR [signal-to-noise ratio]) that is, the difference between the speech presentation and noise level at the point the patient achieves $50 \%$ speech perception $\left(\mathrm{SRT}_{50}\right)$. The noise level must be held constant at $65 \mathrm{~dB}$ SPL while the speech level changes. The measurement must be performed unilaterally excluding the contralateral ear, in the unaided condition, and optionally also with an optimized $\mathrm{HA}$ in the aided condition. We recommend a minimum standard of $\mathrm{S}_{0} \mathrm{~N}_{0}$ azimuth, that is, frontal presentation of the signal and the noise (from the same speaker).

Depending on the test results, training might be necessary. For example, in the International matrix test (IMT), subjects must be acquainted with the speech material and the procedure in order to avoid training effects [Wagener, 1999]. In this case, the presentation of 2 lists is suggested: (1) a list at a well-recognized, fixed speech level in quiet as an example and (2) in the adaptive mode in noise, starting from an SNR well above $\mathrm{SRT}_{50}$ (e.g., $+10 \mathrm{~dB}$ SNR) to train the procedure [HörTech, 2014]. Other tests may require different familiarization procedures.

Hey et al. [Hey et al., 2014] reported that an SRT measured by the OLSA of greater than approximately $2 \mathrm{~dB}$ 
leads to results with poor reproducibility in cochlear-implanted subjects. However, it has to be taken into consideration that users of middle ear implants have a better acoustic reserve i.e., better $\mathrm{BC}$ threshold than $\mathrm{CI}$ users. If the $\mathrm{SRT}_{50}$ result is equal to or higher than $5 \mathrm{~dB}$ SNR $(\geq 5$ $\mathrm{dB}$ SNR), it shall be defined as "not measurable" and should be shown as "not measurable" on graphs. However, in statistical evaluations, it is recommended to assume a fictitious $\mathrm{SRT}_{50}$ value of $5 \mathrm{~dB}$ SNR as the best-case estimate. In this way, a fictitious best-case estimate $\mathrm{SRT}_{50}$ of $5 \mathrm{~dB}$ SNR is distinguishable from a real $\mathrm{SRT}_{50}$ value $(<5$ $\mathrm{dB}$ SNR) that would be measured and recorded as such.

Nevertheless, this procedure is intended to identify estimated values and to limit errors in data and statistics when a fixed noise presentation level of $65 \mathrm{~dB}$ SPL is used. The main limitation arises from the fact that patients with a certain severity of hearing loss will not be able to hear the noise and therefore hearing in quiet instead of hearing in noise is determined. The limit for a fixed noise level of $65 \mathrm{~dB}$ SPL can be expected at a hearing loss between 47 dB HL [Wardenga et al., 2015] and approx. $50 \mathrm{~dB}$ HL, assuming it is a "hearing loss comparable with attenuation" [Plomp, 1978]. Here, we suggest the commonly used fixed noise level of $65 \mathrm{~dB}$ SPL in combination with the limitation described above that covers a broad range of hearing losses up to approxately $47 \mathrm{~dB}$ HL. However, in the future, the range for the determination of $\mathrm{SRT}_{50}$ results in noise may be extended using higher noise levels and we encourage this usage when validated ranges are available.

For the German language, the OLSA test (German version of the international matrix test (IMT)) can be used. Our proposal is easily extendable to other languages, as the IMT (http://www.hoertech.de/en/medical-devices/ intma.html) is available for a variety of different languages. Nevertheless, other comparable tests for which reference data exist may also be used.

Post-Op Procedures: We recommend reporting on the monaurally-aided SRT results after an acclimatization time of at least 6 months. Because of test-retest and learning effects as well as for better comparison, it is useful to perform the unaided test again and report these results as well.

Pure Tone Average, Functional and Effective Gain

There are inconsistencies in the literature regarding the relevant frequencies used to calculate the pure tone average (PTA; American Academy of Otolaryngology Committee on Hearing and Equilibrium, 1979; Bruchhage et al., 2017; Dobie, 2011). To provide a common foundation, we recommend the mean threshold of four frequencies with octave steps from $0.5,1,2$ and $4 \mathrm{kHz}$ to be used for the PTA (PTA4).

The functional gain (FG) is defined as the mean difference between unaided and aided thresholds. It is a helpful tool to give a quick impression about the hearing benefit provided by hearing devices, but it does not contain any information about the frequency characteristics and the aided hearing level. Therefore, we encourage reporting of both the FG and aided thresholds. For calculation of the FG, we recommend using the PTA4 $(0.5,1,2,4 \mathrm{kHz})$ to compare the unaided and aided sound field thresholds.

Although the FG is helpful to describe the real-life patient benefit, since it describes the effect of the device, it cannot be effectively used for the technical characterization of the device, as AMEIs (and bone conduction devices) may be used to provide the sound stimulus directly to the cochlea (e.g. bone conduction devices and AMEI for conductive and mixed hearing loss). Here, we encourage the use of effective gain (EG), which is the difference between aided sound-field threshold and BC threshold that describes the amplification relative to the sensorineural hearing loss and is independent of air-bone-gaps. The data reported according to this standard (Table 1) includes all necessary data to calculate the EG in the range of 0.5 to $6.0 \mathrm{kHz}$. If publication of the EG is desired, we recommend reporting on the frequency-specific or at least the average $(0.5,1,2,4 \mathrm{kHz}) \mathrm{EG}$ to enable better comparison between devices and coupling options.

\section{Follow-Up Time}

The minimum follow-up time after device activation is 12 months. For reporting purposes, we recommend presenting data from at least 6 months post-activation. Data reported as long-term results should be collected from at least 12 months post-activation. To avoid measurement failures that can result from too much time passing between pre- and post-op visits, it is recommendable (if possible) to report the unaided results from the same visit as the one the aided results were collected from.

\section{Safety Outcomes}

Pre-Op Procedures: Usually, safety considerations correspond to good clinical practice and are not relevant for reporting purposes. However, if a patient does not fulfill the inclusion criteria for the intended therapy, the reason for device selection as well as off-label use should be mentioned.

Post-Op Procedures: The minimal standard for the evaluation of clinical safety is the comparison of $\mathrm{BC}$ 
thresholds in the implanted ear to the pre-op assessed BC thresholds. Any adverse event (AE) occurring due to the therapy must be reported by at least 6 months following the surgery. All complications and revision surgeries should be reported and marked as therapy-related or not. The absence of complications or AEs and their resolution during the study period should also be clearly declared in the report.

\section{Subjective Outcomes}

To assess subjective outcomes, we recommend using patient-reported outcome measures, as they are an important diagnostic element in audiology.

The group of experts discussed the advantages and disadvantages of both hearing-specific, patient-reported outcome measures, for example, the Abbreviated Profile of Hearing Aid Benefit (APHAB) and the International Outcome Inventory for Hearing Aids (IOI-HA) as well as generic QoL questionnaires, for example, the Health Utility Index (HUI) Mk 2 and 3, the RAND 36-item Short Form Health Survey (SF-36), and the Glasgow Benefit Inventory (GBI).

The criteria and rationale we used were as follows: (1) each questionnaire should include hearing-specific questions and be validated, (2) the questionnaire should be free of charge as financial burden can pose a barrier to the implementation of a questionnaire in a study, (3) the number of questions and thus the time required to complete the questionnaire should be reasonably small and (4) the questionnaire should be available in multiple languages.

The APHAB [Cox, 1997; Cox and Alexander, 1995] is a validated self-report questionnaire that is used to quantify the impact of a hearing problem on an individual's daily life. Originally the APHAB was used in Englishspeaking (American) adults to evaluate their communication with other people or perceived difficulty with sound recognition in various conditions. It is a useful tool for quantifying the disability associated with hearing loss and the reduction of the disability with amplification [House et al., 2010]. It is a hearing disability-specific questionnaire that assesses auditory functioning with 24 items scored in four 6-item subscales. It produces scores for unaided and aided conditions, and benefit is calculated by comparing the patient's reported difficulty in the unaided condition with their difficulty while using amplification. In Germany, the APHAB is regularly used for hearing aid fitting [Lohler et al., 2016; Lohler et al., 2012]. This free-of-charge questionnaire has been translated into 20 languages. In a study with 224 German-speaking patients, Löhler et al. [Lohler et al., 2010] compared the
APHAB outcome measured pre- and post-fitting with the US (English speaking) norm. They concluded that patients fitted in a German ENT practice score similarly to patients fitted by audiologists in the United States. The APHAB was selected as the minimum reporting standard to assess subjective benefit.

Since the patient should answer the questions based on his/her everyday experience (to minimize bias), it is important that the patient understands how to complete the questionnaire and has ample time to do so before undergoing any audiological tests. This is normally about 10 min or less. Since the questionnaire contains information regarding unaided and aided performance as well as hearing benefit, if the patient completes it both pre- as well as post-operatively, it provides a sensitive instrument to detect the benefit of the intervention [de Almeida and Taguchi, 2004]. In addition to the audiological evaluation, the post-op subjective benefit evaluation should be performed in the presence of stable audiological results about 6 months after device activation or one month after a stable fitting, depending on which occurs first.

Considering this, we recommend assessing subjective satisfaction preoperatively with a hearing aid (in the ear to be implanted) and postoperatively with the AMEI using the APHAB 6 and 12 months after the patient's first fitting.

\section{Discussion}

In recent years, AMEI have extended the range of treatment options for sensorineural and mixed hearing loss significantly, and they have helped to provide better surgical solutions for patients with previously insufficient audiological rehabilitation. Although they overlap in indication ranges with CI and conventional hearing aids, they are in a class of their own that shares many properties with these other devices as well as many differences. For example, the level of invasiveness is comparable to CIs, but in terms of the amount of residual hearing required for sufficient benefit, they may be better compared to HAs. Minimal outcome measurements used for CI [Kleine Punte and Van de Heyning, 2013] or intended for the full range of hearing loss treatments [Gurgel et al., 2012] do not cover the relevant AMEI-specific properties and are therefore inappropriate to use with AMEIs. Tysome et al. [Tysome et al., 2010] concludes that the overall quality of AMEI studies is moderate to poor because of a lack of comparison with conventional hearing aids. Furthermore, pooling data on an international or multicentre ba- 
sis to extend the statistical basis is not possible due to the large heterogeneity of tests and settings used to report audiological results, AEs and QoL measures. Independent meta-analyses are required to clinically verify indication ranges, enable cross-site comparison, determine long-term results and enable comparisons between device classes to decide about reimbursement strategies.

The intention of the minimal reporting standards proposed here was to define an essential core data set that is both currently available as well as easily implemented into clinical routine. They should also be able to be extended according to the specific needs of the investigated application, to enable comparison and pooling of results to create convincing evidence in meta-analyses.

Although developed initially for the German language, the proposal seeks to minimize language-specific elements to make it easily extendable to other languages. For the suggested monosyllabic test, reference data exists in many languages and the international matrix test proposed is available in a variety of languages as well (http:// www.hoertech.de/en/medical-devices/intma.html). However, comparability may be difficult or impossible for some language groups such as tonal languages and this has to be addressed in future investigations.

As with any complex intervention, the treatment with AMEIs encompasses a broad range of relevant information including the indication, the surgical intervention, necessary after-care and long-term follow up. However, the minimal reporting guidelines focus on the medical aspects relevant for the evaluation of the benefit of AMEI treatment.

In the future, it will be of interest to assess and report in long-term follow-ups on how long the AMEI hearing rehabilitation procedure leads to a sufficient hearing outcome without medical problems, or the disease-free-survival, given by technical and medical constraints. Equally important are the audiological aspects, such as what percentage of patients still benefit from the procedure/device after 3, 5 or 10 years, or conversely, how many patients eventually required a different solution (e.g., a cochlear implant).

The audiological measurements suggested here were intended to be feasible with standard calibrated equipment in a limited timeframe, utilizing the common expertise of clinical personnel conducting routine examinations. AC and BC pure tone thresholds obtained at least at the most speech-relevant frequencies should make it possible to trace the impact of the intervention and longterm results. Sound field thresholds should allow for comparison to HAs and can be used to determine "func- tional" and "effective gain." The maximum monosyllabic WRS for phonemically balanced words $\left(\mathrm{WRS}_{\max }\right.$ ) via headphones serves as an important preoperative indicator for later success in assessing cochlear reserve and dead regions [Hoppe et al., 2015]. The WRS has to be measured at a fixed sound pressure level $(65 \mathrm{~dB})$ to measure speech perception improvements induced by AMEIs. Reporting WRS measured at a fixed-sensation level of $40 \mathrm{~dB}$ above SL, as suggested by Gurgel et al. [Gurgel et al., 2012]) would already show a ceiling effect before implantation and would therefore not be sensitive for AMEI-induced improvement and would not allow for a parametric measurement of hearing improvement [Mueller et al., 2017]. Furthermore, the use of a fixed SPL for WRS measurements would allow sufficient sample size estimation for prospective trials. Speech intelligibility in quiet and noise is required with at least frontal sound presentation $\left(\mathrm{S}_{0} \mathrm{~N}_{0}\right)$. For measurement of special acoustic processing features of audio processors, the use of further spatially separated sound sources is advised.

We propose using the APHAB to evaluate subjective benefit with AMEIs. Administration of the APHAB before and after hearing aid fitting proved to be a valuable and sensitive method to detect the benefit of the intervention [de Almeida and Taguchi, 2004]. One of its advantages is that in most analyses, significant relationships between audiometric data and at least 3 of the 4 APHAB subscales that reflect speech communication (Ease of communication, Reverberation, Background noise) can be found [Löhler, 2017]. The APHAB has been used as a subjective assessment scale in several studies on middle ear implantation [Fraysse et al., 2001; Jenkins et al., 2004; Lenarz et al., 2001; Luetje et al., 2002; Todt et al., 2002; Uziel et al., 2003]. In these studies, comparisons were made between APHAB scores obtained before implantation, while the patient was still using his conventional hearing aids and those obtained after implantation. In general, significant changes have been reported, which indicates that implanted patients experience improvements with their AMEI compared to their conventional hearing aid. However, it should be noted that the level of commitment involved in choosing to undergo an invasive treatment might bias the outcomes. Cox and Alexander reported reference APHAB scores obtained in a group of patients with moderate-tosevere hearing loss fitted with conventional linear hearing aids [Cox and Alexander, 1995].

As more specific QoL measures and patient-reported outcomes will be developed and internationally validated in the future, these will likely need to be added to the minimal reporting outcome data sets. 
Statistical comparison of data from different sources was one of the main issues addressed as it allows for the creation of meta-analyses. Here the use of a template (see online suppl. 1 www.karger.com/doi/10.1159/000490878 for version 1.0 (updated versions can be found at https:// cdn.hno.org/media/publikationen/minimal_standards_ for_AMEI_v1.0.xlsx and https://www.dga-ev.com/ fachausschuesse/)) is suggested to facilitate pooling of audiological data and the classification of medical categories.

\section{Conclusion}

This manuscript suggests minimal reporting standards for publications in the field of Active Middle Ear Hearing Implants, since reporting of studies has been in- adequate and extremely heterogeneous up to now. Hopefully, these standards will be taken into consideration when presenting results of original studies, systematic reviews, and meta-analyses.

\section{Statement of Ethics}

Not applicable, as no human subjects/animal experiments are involved.

\section{Disclosure Statement}

This project was initiated by Med-El and all authors received travel support by Med-El to the committee meetings for discussion and completion of the here presented manuscript. In all aspects concerning the content of the manuscript, all authors were independent to decide.

\section{References}

American Academy of Otolaryngology - Head and Neck Surgery Foundation I: Committee on Hearing and Equilibrium guidelines for the evaluation of results of treatment of conductive hearing loss. Otolaryngol Head Neck Surg 1995;113:186-187.

American Academy of Otolaryngology Committee on Hearing and Equilibrium atACoOCotMAoN: Guide for the evaluation of hearing handicap. JAMA 1979;241:2055-2059.

Becvarovski Z, Kartush JM: Smoking and tympanoplasty: implications for prognosis and the Middle Ear Risk Index (MERI). Laryngoscope 2001;111:1806-1811.

Bellucci RJ: Selection of cases and classification of tympanoplasty. Otolaryngol Clin North Am 1989;22:911-926.

Bond M, Elston J, Mealing S, Anderson R, Weiner G, Taylor RS, Liu Z, Stein K: Effectiveness of multi-channel unilateral cochlear implants for profoundly deaf children: a systematic review. Clin Otolaryngol 2009;34:199-211.

Brand T, Hohmann V: An adaptive procedure for categorical loudness scaling. J Acoust Soc Am 2002;112:1597-1604.

Bruchhage KL, Leichtle A, Schonweiler R, Todt I, Baumgartner WD, Frenzel H, Wollenberg B: Systematic review to evaluate the safety, efficacy and economical outcomes of the Vibrant Soundbridge for the treatment of sensorineural hearing loss. Eur Arch Otorhinolaryngol 2017;274:1797-1806.

Colquitt JL, Loveman E, Baguley DM, Mitchell TE, Sheehan PZ, Harris P, Proops DW, Jones J, Clegg AJ, Welch K: Bone-anchored hearing aids for people with bilateral hearing impairment: a systematic review. Clin Otolaryngol 2011;36:419-441.
Cox R: The APHAB - Administration and Application of the APHAB. HearJ 1997;50:32-48.

Cox RM, Alexander GC: The abbreviated profile of hearing aid benefit. Ear Hear 1995; 16:176186.

de Almeida K, Taguchi CK: (The use of the selfassessment questionnaire to evaluate hearing aid benefit). Pro Fono 2004;16:101-110.

Dobie RA: The AMA method of estimation of hearing disability: a validation study. Ear Hear 2011;32:732-740.

Dornhoffer JL, Gardner E: Prognostic factors in ossiculoplasty: a statistical staging system. Otol Neurotol 2001;22:299-304

Ernst A, Todt I, Wagner J: Safety and effectiveness of the Vibrant Soundbridge in treating conductive and mixed hearing loss: a systematic review. Laryngoscope 2016;126:1451-1457.

Fouché C, Light G: An Invitation to Dialogue "The World Café" In Social Work Research, 2011.

Fraysse B, Lavieille JP, Schmerber S, Enee V, Truy E, Vincent C, Vaneecloo FM, Sterkers O: A multicenter study of the Vibrant Soundbridge middle ear implant: early clinical results and experience. Otol Neurotol 2001;22:952-961.

Frenzel H, Sprinzl G, Widmann G, Petersen D, Wollenberg B, Mohr C: Grading system for the selection of patients with congenital aural atresia for active middle ear implants. Neuroradiology 2013;55:895-911.

Gavilan J, Adunka O, Agrawal S, Atlas M, Baumgartner WD, Brill S, Bruce I, Buchman C, Caversaccio M, De Bodt MT, Dillon M, Godey B, Green K, Gstoettner W, Hagen R, Hagr A, Han D, Kameswaran M, Karltorp E, Kompis M, Kuzovkov V, Lassaletta L, Li Y, Lorens A, Martin J, Manoj M, Mertens G,
Mlynski R, Mueller J, O’Driscoll M, Parnes L, Pulibalathingal S, Radeloff A, Raine $\mathrm{CH}, \mathrm{Ra}-$ jan G, Rajeswaran R, Schmutzhard J, Skarzynski H, Skarzynski P, Sprinzl G, Staecker H, Stephan K, Sugarova S, Tavora D, Usami S, Yanov Y, Zernotti M, Zorowka P, de Heyning PV: Quality standards for bone conduction implants. Acta Otolaryngol 2015;135:12771285.

Godey B: Quality standards for middle ear implantation. Cochlear Implants Int 2013; 14(suppl 2):S21-S26.

Gurgel RK, Jackler RK, Dobie RA, Popelka GR: A new standardized format for reporting hearing outcome in clinical trials. Otolaryngol Head Neck Surg 2012;147:803-807.

Hagen R: Quality standards for combined electric and acoustic stimulation. Cochlear Implants Int 2013;14(suppl 2):S27-S33.

Hey M, Hocke T, Hedderich J, Muller-Deile J: Investigation of a matrix sentence test in noise: reproducibility and discrimination function in cochlear implant patients. Int J Audiol 2014;53:895-902.

Hobson JC, Roper AJ, Andrew R, Rothera MP, Hill P, Green KM: Complications of bone-anchored hearing aid implantation. J Laryngol Otol 2010;124:132-136.

Hoppe U, Hast A, Hocke T: (Speech perception with hearing aids in comparison to pure-tone hearing loss). HNO 2014;62:443-448.

Hoppe U, Hast A, Hocke T: Audiometry-based screening procedure for cochlear implant candidacy. Otol Neurotol 2015;36:10011005.

HörTech G: International Matrix Tests: Reliable speech audiometry in noise, 2014, pp 4, "Typical use of Matrix Tests." 
House JW, Kutz JW Jr, Chung J, Fisher LM: Boneanchored hearing aid subjective benefit for unilateral deafness. Laryngoscope 2010;120: 601-607.

Jahrsdoerfer RA, Yeakley JW, Aguilar EA, Cole RR, Gray LC: Grading system for the selection of patients with congenital aural atresia. Am J Otol 1992;13:6-12.

Jenkins HA, Niparko JK, Slattery WH, Neely JG, Fredrickson JM: Otologics Middle Ear Transducer Ossicular Stimulator: performance results with varying degrees of sensorineural hearing loss. Acta Otolaryngol 2004;124:391394.

Johnson CE, Danhauer JL, Reith AC, Latiolais $\mathrm{LN}$ : A systematic review of the nonacoustic benefits of bone-anchored hearing AIDS. Ear Hear 2006;27:703-713.

Klein K, Nardelli A, Stafinski T: A systematic review of the safety and effectiveness of fully implantable middle ear hearing devices: the carina and esteem systems. Otol Neurotol 2012; 33:916-921.

Klein K, Nardelli A, Stafinski T: A systematic review of the safety and effectiveness of the $\mathrm{Vi}$ brant Soundbridge. J Otol Rhinol 2013;2:1-6.

Kleine Punte A, Van de Heyning P: Quality standards for minimal outcome measurements in adults and children. Cochlear Implants Int 2013;14(suppl 2):S39-S42.

Lassaletta L, Calvino M, Zernotti M, Gavilan J: Postoperative pain in patients undergoing a transcutaneous active bone conduction implant (Bonebridge). Eur Arch Otorhinolaryngol 2016;273:4103-4110.

Lenarz T, Weber BP, Issing PR, Gnadeberg D, Ambjornsen K, Mack KF, Winter M: (Vibrant Sound Bridge System. A new kind hearing prosthesis for patients with sensorineural hearing loss. 2. Audiological results). Laryngorhinootologie 2001;80:370-380.

Lohler J, Akcicek B, Wollenberg B, Schonweiler R: (Distribution and Scattering of APHAB Answers Before and After Hearing Aid Fitting). Laryngorhinootologie 2016;95:768-773.

Lohler J, Frohburg R, Moser L: (The use of the German APHAB for quality control in hear- ing aid fitting in an ENT-office. Comparison of our results with the given US-norm). Laryngorhinootologie 2010;89:737-744.

Lohler J, Moser L, Heinrich D, Hormann K, Walther LE: (Results of clinical use of the German version of the APHAB). HNO 2012;60:626636.

Löhler J, Wollenberg B, Schönweller R: [APHAB scores for individual assessment of the benefit of hearing aid fitting]. HNO 2017;65:901909.

Luetje CM, Brackman D, Balkany TJ, Maw J, Baker RS, Kelsall D, Backous D, Miyamoto R, Parisier S, Arts A: Phase III clinical trial results with the Vibrant Soundbridge implantable middle ear hearing device: a prospective controlled multicenter study. Otolaryngol Head Neck Surg 2002;126:97-107.

Martin FC, JG: Introduction to Audiology (ed 11), 2012.

Martin J, Raine CH: Quality standards for cochlear implantation in children and young adults. Cochlear Implants Int 2013;14(suppl 2):S13S20.

Mohamad S, Khan I, Hey SY, Hussain SS: A systematic review on skin complications of bone-anchored hearing aids in relation to surgical techniques. Eur Arch Otorhinolaryngol 2016;273:559-565.

Müller J, PlontkeSK, Rahne T: [Speech audiometric outcome parameters in clinical trials on hearing improvement.] HNO 2017;65:211-218.

Neudert M, Zahnert T: Tympanoplasty - news and new perspectives. GMS Curr Top Otorhinolaryngol Head Neck Surg 2017;16:Doc07. doi: 10.3205/cto000146. eCollection 2017.

Pastoors AD, Gebhart TM, Kiessling J: A fitting strategy for digital hearing aids based on loudness and sound quality. Scand Audiol Suppl 2001;60-64.

Plomp R: Auditory handicap of hearing impairment and the limited benefit of hearing aids. J Acoust Soc Am 1978;63:533-549.

Siegert R, Weerda H, Mayer T, Bruckmann H: (High resolution computerized tomography of middle ear abnormalities). Laryngorhinootologie 1996;75:187-194.
Stewart A: On conversation and collective questioning: theory and practice of the World Café. System Thinker 2005;16:9-10.

Todt I, Seidl RO, Gross M, Ernst A: Comparison of different vibrant soundbridge audioprocessors with conventional hearing aids. Otol Neurotol 2002;23:669-673.

Tos M: Cartilage tympanoplasty methods: proposal of a classification. Otolaryngol Head Neck Surg 2008;139:747-758.

Tysome JR, Moorthy R, Lee A, Jiang D, O'Connor AF: Systematic review of middle ear implants: do they improve hearing as much as conventional hearing AIDS? Otol Neurotol 2010;31: 1369-1375.

Uziel A, Mondain M, Hagen P, Dejean F, Doucet G: Rehabilitation for high-frequency sensorineural hearing impairment in adults with the symphonix vibrant soundbridge: a comparative study. Otol Neurotol 2003;24:775783

Van Rompaey V, Claes G, Verstraeten N, van Dinther J, Zarowski A, Offeciers E, Somers T: Skin reactions following BAHA surgery using the skin flap dermatome technique. Eur Arch Otorhinolaryngol 2011;268:373-376.

Wagener KCB T, Kollmeier B: Development and evaluation of a German sentence test. Part III: Evaluation of the Oldenburg sentence test. [Entwicklung und Evaluation eines Satztests für die deutsche Sprache - Teil III: Evaluation des Oldenburger Satztests]. Z Audiol 1999; 86-95.

Wardenga N, Batsoulis C, Wagener KC, Brand T, Lenarz T, Maier H: Do you hear the noise? The German matrix sentence test with a fixed noise level in subjects with normal hearing and hearing impairment. Int J Audiol 2015; 54(suppl 2):71-79.

Wazen JJ, Wycherly B, Daugherty J: Complications of bone-anchored hearing devices. Adv Otorhinolaryngol 2011;71:63-72.

Zwartenkot JW, Mulder JJ, Snik AF, Cremers CW, Mylanus EA: Active middle ear implantation: long-term medical and technical follow-up, implant survival, and complications. Otol Neurotol 2016;37:513-519. 